\title{
Encarnac(c)iones del multiculturalismo en dos festivales afromusicales de Colombia y México
}

\author{
MATEO PAZOS CÁRDENAS
}

En este artículo se analizan las maneras en que el discurso multicultural contemporáneo de los Estados-nación latinoamericanos se imbrica en las prácticas y representaciones corporales de las personas asistentes a dos festivales, uno en Colombia y otro en México, que se articulan alrededor de tradiciones musicales afroamericanas. Se hace uso de una metodología cualitativa basada en etnografías de ambos eventos y en entrevistas con asistentes recurrentes a los festivales, para destacar sus experiencias corporales en estos escenarios, las cuales están mediadas por la categoría étnico-racial o de color de piel. El texto demuestra que estos espacios festivos reproducen los presupuestos racistas bajo los que se construye el proyecto multicultural en Latinoamérica.

PALABRAS CLAVE: corporalidades, multiculturalismo, poblaciones afrolatinoamericanas, encarnación, racismo

Embodiments of Multiculturalism in Two Afromusic Festivals in Colombia and Mexico

The paper analyzes the ways in which the contemporary multicultural discourse of Latin American nation-States overlaps in body practices and representations of people attending festivals, one in Colombia and another in Mexico, that render afro-american musical traditions. A qualitative methodology is used, based on an etnographic review of both events and interviews with people recurrently attending these festivals to demonstrate their body experiences in these events which are mediated by racial-ethnic or skin-color categories. The text shows that these festive spaces reproduce the racist assumptions under which the multicultural project is built in Latin America.

KEYWORDS: corporalitites, multiculturalism, afro-latinoamerican populations,

Mateo Pazos Cárdenas embodiment, racism 


\section{Introducción: debates sobre corporalidades y multiculturalismo en Latinoamérica}

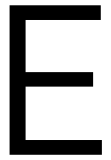

1 multiculturalismo ha sido uno de los temas más recurrentes de la disciplina antropológica en la región latinoamericana desde la última década del siglo XX. Gracias a las transformaciones sociales acaecidas en el mundo en la época posterior a la Segunda Guerra Mundial y a las disputas políticas encabezadas por numerosos grupos étnicos en varios países de la región, que tomaron fuerza en las décadas de 1960 y 1970, el multiculturalismo se ha constituido como un campo de batalla, de correlación de fuerzas entre actores sociales. Por una parte, este escenario ha expresado los intereses particulares de las elites nacionales blanco-mestizas, pero a la vez, las reivindicaciones y movilizaciones sociales y políticas de poblaciones indígenas y afrodescendientes que buscan una inclusión diferenciada y digna dentro de los marcos legislativos nacionales contemporáneos (Gros, 2000; Wade, 2000; 2008b).

La aparición, legislación y aceptación del proyecto multicultural precisó la promulgación de una serie de políticas públicas y la creación de un marco legal que se encargara de velar y — en teoría - hacer cumplir los derechos y deberes de las poblaciones representantes de esta diversidad cultural en su devenir sociocultural y político (Gros, 2000; De Carvalho, 2004; Segato, 2007; Wade, 2000; 2008b). Esto ha implicado un proceso en el cual el Estado-nación necesita un actor étnico constituido con claridad, reconocido y legitimado, con quien negociar su propia intervención y la inclusión de éste en la sociedad nacional. La "etnificación" de ciertos sujetos por parte del Estado-nación implica, en palabras de Eduardo Restrepo (2004), una “tecnología de normalización”, que inventa y estandariza ciertas tradiciones, prácticas, subjetividades e identidades étnicas. El proyecto multicultural ejecutado por la mayoría de los gobiernos de los Estados-nación latinoamericanos reconoce y acepta las diferencias culturales para homogeneizar y centralizar el ejercicio de poder sobre las personas que están bajo su jurisdicción político-administrativa: la ciudadanía nacional (Gros, 2000; De Carvalho, 2004; Segato, 2007). 
Dicho esto, las intersecciones entre los estudios del multiculturalismo y los análisis sobre las corporalidades han sido mucho menos tratadas en nuestra región (Viveros, 2000; Walmsley, 2005; Citro, Aschieri y Mennelli, 2011; Muñiz, 2004; 2013). El análisis que se propone en este artículo incluye la performatividad de los cuerpos en su apropiación y significación de discursos, como el del multiculturalismo, que propende a "concebir al sujeto encarnado, más que dueño de su cuerpo" (Muñiz, 2013: 93), y además, "un cambio de entender la cultura como escrita a encarnada y performatizada" (Castañeda, 2012: 97). Por esto, se problematizan las maneras en que el discurso multicultural de los Estados-nación latinoamericanos contemporáneos puede rastrearse y analizarse en las prácticas y representaciones corporales de las personas asistentes a dos festivales afromusicales, ${ }^{1}$ el Festival Internacional Afrocaribeño en la ciudad de Veracruz, México, y el Festival de Músicas del Pacífico "Petronio Álvarez" en la ciudad de Cali, Colombia. Se han privilegiado estos espacios festivos como lugares de la preocupación investigativa al ser situaciones sociales en las que los cuerpos y las corporalidades entran en tensión en medio de dos discursos: por un lado, la concepción moderna del cuerpo como un elemento que debe ser borrado, separado de sí mismo y de los demás mediante una racionalización extrema, y por el otro, la concepción pasional y comunitaria del cuerpo que brindan los momentos de fiesta y carnaval (Le Breton, 2005), espacios considerados como campos de batalla en los que se pone en juego la construcción de identidades (Guss, 2000).

Con la metodología cualitativa, basada en el trabajo de campo de varios años de asistencia a los dos festivales y en entrevistas a personas que han acudido de manera recurrente, se busca explicar las formas en que la diversidad étnico-cultural es significada, apropiada y encarnada en estos escenarios festivos por el público asistente. El foco de análisis es la construcción de sus prácticas corporales y su percepción de los demás durante estos eventos.
El artículo se divide en tres apartados. Los primeros dos describen y analizan las principales tensiones en la construcción y encarnación de identidades e identificaciones por parte de los sujetos asistentes a los dos festivales. En un momento posterior, se realiza un análisis paralelo para identificar puntos de intersección y distanciamiento en los dos casos, bajo la luz del proyecto multicultural hegemónico latinoamericano. Para finalizar, se presentan unas breves reflexiones finales.

\section{El Festival de Músicas del Pacífico "Petronio Álvarez": tradiciones y estereotipos corporales en tensión}

El Festival de Músicas del Pacífico "Petronio Álvarez" se lleva a cabo cada año en agosto, en la ciudad de Cali, Colombia. Mediante el formato de concurso, se presentan diversos géneros y aires musicales de la región del Pacífico colombiano. ${ }^{2}$ El Festival surgió

"Afromusicales" en la medida en que tienen el propósito de poner en escena ritmos y géneros relacionados con tradiciones musicales pertenecientes a los conjuntos culturales de los grupos afrodescendientes de Colombia y México, aunque también, en menor proporción, de otros países pertenecientes al universo afrodiaspórico.

2 La región del Pacífico es una división ambiental y cultural conformada por cuatro departamentos: Chocó, Valle del Cauca, Cauca y Nariño. Sus límites son la Cordillera Occidental -vertiente izquierda de la ramificación de la cordillera de los Andes en el territorio colombiano- y el océano Pacífico en su margen occidental. De acuerdo con el Censo general 2005, 10.3\% de la población del país se reconoce como afrodescendiente -4311757 personas-, y en la región del Pacífico se concentra 44\% de ese total -1904732 personas- (DANE, 2006). Más allá de las críticas hacia las cifras concretas, principalmente por el subregistro estadístico y la invisibilización de otras categorías étnicas de identificación relacionadas, como "negro" o "moreno", así como la desactualización del estudio -es el último censo nacional existente-, es claro que casi la mitad de la población que se reconoce como afrodescendiente en el país habita esta región. 
a finales de la década de 1990, gracias a la idea de un funcionario público local, Germán Patiño Ossa, y a su genuino interés en la música de esta región. Mediante el puesto político que ocupaba entonces, formuló el proyecto como un tributo y una estrategia de reconocimiento a la herencia "afro" de la ciudad de Cali, cuyos espacios geográficos y culturales han sido históricamente habitados y construidos, en gran medida, por poblaciones afrodescendientes. ${ }^{3}$

Quisiera describir de manera sucinta la experiencia corporal de estar en el Festival en condición de asistente, condición que está ligada al baile y la arrechera de manera intrínseca. ${ }^{4} \mathrm{El}$ público se compone de varios grupos sociales de la ciudad de Cali. Aunque en un principio se puso énfasis en la población afrocolombiana, desde 2007 la concurrencia se popularizó y masificó, y ha ganado gran asistencia de personas no afrodescendientes, tanto de la ciudad como de otras regiones del país.

El baile de los asistentes al Festival es una de sus características principales, pues es la respuesta a las músicas que se interpretan en la tarima. Éste puede ser individual, en pareja, en grupo o con coreografías, y suele acompañarse de algunos elementos, como pañuelos y abanicos. Los pañuelos —al parecer, por tradición son blancos, aunque se ven de todos los colores, tamaños y motivos - se mueven con una o dos manos por encima de la cabeza. Tanto hombres como mujeres los usan. Según las palabras de los presentadores del Festival y de algunos entrevistados, representan el movimiento del agua, de las olas del mar y los ríos, elementos fundamentales en la concepción del territorio de las comunidades afrocolombianas del Pacífico. Los abanicos son portados en particular por las mujeres, que los usan como recurso dancístico y para refrescarse a sí mismas o a sus parejas en momentos en que el calor expedido por los miles de cuerpos en rozamiento constante se vuelve insoportable.

En este contexto, ¿cómo se expresa el discurso multicultural en los cuerpos y prácticas corporales de los asistentes? Para comenzar a responder esta interrogante, quisiera diferenciar, en un primer momento, las opiniones de los asistentes afrocolombianos de los no afrocolombianos. En las entrevistas con asistentes al Festival que no se autodefinen como afrocolombianos son constantes las narrativas sobre la representación de la forma de bailar y la expresión corporal de las personas afrocolombianas que asisten al "Petronio":

Cuando uno habla de la costa pacífica, del "Petronio", te viene a la mente la forma como se expresan, el movimiento y el "tumbao" que tienen (entrevista con informante F, mujer, Cali, Colombia, 10 de febrero de 2015). ${ }^{5}$

El swing, el sabor, el movimiento del negro. El negro es más... caliente. El blanco es muy parco,

Santiago de Cali fue receptora de numerosas poblaciones afrodescendientes esclavas y libertas durante los periodos colonial y republicano, vinculadas a la explotación minera de la región del Pacífico colombiano y posteriormente a los cultivos de caña de azúcar del valle geográfico del río Cauca. En 1926, comenzó la construcción de la carretera CaliBuenaventura - principal puerto del Pacífico colombiano y municipio habitado casi en su totalidad por población afrodescendiente-, conexión que había sufrido grandes tropiezos en 1915 por la construcción de la línea ferroviaria. Esta circunstancia permitió múltiples intercambios culturales y demográficos entre las dos ciudades. Durante la segunda mitad del siglo xx y hasta la actualidad, Cali ha sido receptora de una gran cantidad de poblaciones "afro" desplazadas por el conflicto armado, con fuertes impactos en la región del Pacífico, por la idea de ser una ciudad amigable con estas poblaciones, incluso menos racista que otras ciudades capitales, suposición fundamentada en la histórica convivencia de personas blanco-mestizas y afrodescendientes. Arrechera es una palabra usada con frecuencia en Colombia, cuyo significado varía de acuerdo con la región o la persona que la use. La acepción más generalizada, o de su adjetivo derivado arrecho-a, la asocia con la excitación sexual. Estar arrecho podría asimilarse a expresiones como "estar caliente", "estar cachondo". Sin embargo, en la región del Pacífico colombiano, los afrocolombianos también la usan para designar otras actitudes: estar contento, sentirse feliz.

5 "Tumbao" hace referencia a la cadencia, ritmo y "sabor" en la manera de bailar de una persona. 
entonces, por más que yo baile currulao o sepa bailarlo, yo bailando al lado del negro, la diferencia es total (entrevista con informante B, hombre, Buga, Colombia, 24 de enero de 2015).

Los negros tienen una cadencia, tienen un movimiento que no lo tenemos nosotros los de piel blanca, rosadita. Ellos no necesitan alardear de movimiento, sino que tienen una rítmica, un movimiento en la cadera y uno lo mira y trata de copiarlo, pero es muy difícil hacerlo igual (entrevista con informante A, mujer, Cali, Colombia, 15 de enero de 2015).

Las representaciones de las corporalidades de las personas afrocolombianas expresadas por los mestizos forman parte de un conjunto de estereotipos de las poblaciones "afro" del país que se repiten de manera constante. ${ }^{6}$ Estos estereotipos apuntan de manera generalizada a asociar a las personas afrodescendientes con la hipersexualidad - lo "caliente", la fogosidad, el buen desempeño sexual, el tamaño del pene de los hombres-, lo dionisiaco - la fiesta, el exceso, el derroche - y un talento innato para el baile (Viveros, 2000; Wade, 2008a; Congolino, 2008). Aunque este conjunto de representaciones conforma la evolución histórica de las significaciones de las personas "afro" y sus tradiciones culturales por parte de las poblaciones mestizas desde el periodo colonial y a lo largo de los siglos XIX y XX (Restrepo, 2007), en el contexto actual ya no se expresan necesariamente en términos de discriminación o racismo, sino que se idealiza e hiperexotiza la diferencia cultural "afro" en términos de características que no se ven como negativas per se. Esto puede relacionarse con la mayor afluencia de públicos no afrocolombianos al "Petronio" - representados en un primer momento y en su mayoría por personas mestizas jóvenes-, que ven en el evento una fiesta diferente y "exótica", que no viven con frecuencia en sus cotidianidades. ${ }^{7}$

Varias investigaciones muestran que, en muchos casos, los estereotipos sobre las características y prácticas sexuales y corporales de las personas "afro" son interiorizadas y reconocidas por las mismas personas afrodescendientes con frases como "es algo genético, está en la sangre, así somos". ${ }^{8}$ Varios de los afrocolombianos entrevistados para esta investigación narran que sí hay una diferenciación de las maneras de bailar con los asistentes "no afro", pero en el entendido de que estos últimos sienten más estas diferencias y tratan de suplirlas imitando a los afrocolombianos:

Se ve muy marcado, porque siempre los blanquitos buscan es eso, el parche de los negros, porque dicen que los negros tienen el sabor, son los que llevan el guaguancó de la rumba (entrevista con informante D, hombre, Cali, Colombia, 2 de febrero de 2015).

En ocasiones uno ve que los blancos están buscando seguir el ritmo de la música, de la marimba, y

Según Mara Viveros (2000), un estereotipo es una idea o comportamiento que se repite de manera automática a partir de un modelo establecido con anterioridad, por medio de determinados procesos socioculturales. Amaranta Castillo (2003) y Mary Congolino (2008) ponen énfasis en la situación de inclusión o exclusión relativa que estos estereotipos imponen a los individuos de acuerdo con el orden social jerarquizado, determinado en términos de clase, género, color de piel, entre otros. Para Stuart Hall, los estereotipos forman parte de los juegos de poder/saber y 'reducen, esencializan, naturalizan y fijan la 'diferencia' [...], son una parte del mantenimiento del orden simbólico y social" (1997: 258).

7 Michael Birenbaum (2012) anota que hay en estos jóvenes mestizos una tendencia a asumir un discurso "antirracista", que aboga por la tolerancia y curiosidad hacia las "culturas negras" colombianas y que puede ser sentido, practicado y/o entendido como una manera de diferenciarse de otros sectores de la sociedad. Sobre esta situación, en el contexto argentino, véase Citro, Aschieri y Mennelli (2011).

8 Para Colombia, véanse Viveros (2000), en las ciudades de Bogotá y Quibdó; Congolino (2008), en la ciudad de Cali. Para Ecuador, Walmsley (2005), en la provincia de Esmeraldas. Para México, Castillo (2003), en la Costa Chica de Oaxaca; Malcomson (2008) y Rinaudo (2008), en el puerto de Veracruz. 


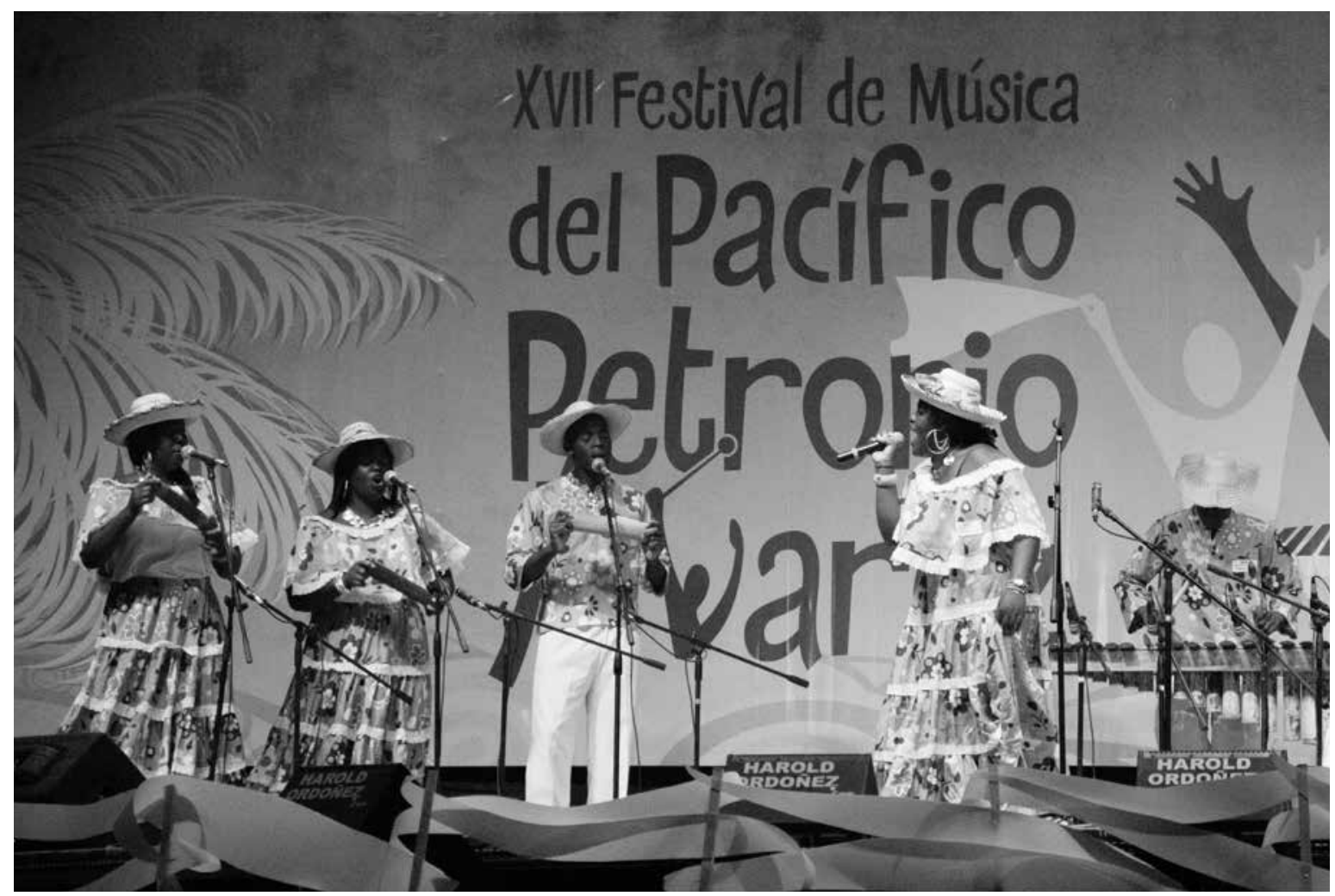

Sol Robayo • Festival "Petronio Álvarez", 23 de septiembre de 2013.

ellos no están muy familiarizados con eso. Entonces, como asumen que "Petronio" es igual a gente negra, se remiten a la gente "afro" que tenga como el sabor, el swing, para poder estar a la altura de nosotros, o aprender, intentar moverse como nosotros (entrevista con informante $\mathrm{B}$, hombre, Buga, Colombia, 24 de enero de 2015).

Decir que todos los afrocolombianos son excelentes bailarines, que son proclives a las fiestas y sus excesos o que tienen un desempeño sexual destacado es borrar la pluralidad intrínseca de la misma diversidad cultural y englobarla dentro de una única manera de ser. Es decir, ésta no es diversa sólo frente a la cultura hegemónica mestiza de un país como Colombia, sino que también es diversa dentro de ella misma. En este sentido, racializar los atributos corporales de manera generalizada es reproducir clasificaciones que inmovilizan la alteridad y solidifican sus identidades y procesos de identificación, que están en transformación permanente. Respecto al baile, es una habilidad que se aprende mediante procesos de socialización y se incorpora a un capital corporal por la familiarización de esta práctica en determinados contextos socioculturales. El hecho de que los afrocolombianos crezcan en entornos en los que se escuchan ciertos ritmos musicales y se realizan ciertos bailes permite que aprendan estas habilidades desde niños, pero no significa que estén "predispuestos de manera innata" a ser bailarines (Desmond, 2003; Walmsley, 2005).

De hecho, las entrevistadas afrocolombianas expresan las diferencias que sienten en sus formas de bailar respecto a otras personas afrocolombianas: 
Yo bailo como he visto que se baila. A veces me siento raro porque hay gente que sabe bailar mucho más y yo bailo lo básico, el movimiento de caderas y ya. Hay veces que me siento incómoda, porque pienso que me están mirando raro porque de pronto no sé bailar bien. Pero me gusta bailarlo (entrevista con informante E, mujer, Cali, Colombia, 3 de febrero de 2015).

Tanta diferencia hay en el baile que no es solamente entre blancos y negros, sino que si vas [a] Guapi o a Timbiquí, la gente baila distinto, tiene otra sazón, otro movimiento. Y si te vas pa'l Chocó, te encontrás otra variedad porque es distinto al Sur. Al Norte encontrás chirimía y acá abajo [en el Sur] currulao. Uno marca los pasos distintos, acá [en el Sur] los marcamos más suave. Y yo me imagino que los negros que viven en Cali bailan distinto también, porque encontramos negros de distintas zonas y tienen una mezcla y deben construir un ritmo propio (entrevista con informante C, mujer, Cali, Colombia, 10 de enero de 2015). ${ }^{9}$

El último aspecto por señalar es la forma en que los asistentes se preparan corporalmente para asistir al "Petronio", es decir, la parafernalia alrededor del vestuario y el peinado presente en muchas de las personas en el Festival: entre las mujeres, turbantes, vestidos con estampados coloridos o trenzas en el cabello; entre los hombres, guayaberas de lino blanco o estampadas y cierto tipo de sombreros. Todo esto se relaciona con la identificación de cierto tipo de estéticas corporales "afro" o tradicionales. Al respecto, los entrevistados afrocolombianos mencionan lo siguiente:

A veces trato de identificarme, de ponerme ropas que me hagan sentir como "afro". Me compré un par de camisetas que se identifican en el lugar, como guayaberas, cosas así, como afrocolombianas [...]. Y uno ve que muchos "afros" en ese momento tratan de reivindicar su cultura, entonces uno suele ver a las mujeres con sus turbantes, con sus trenzas, con sus cosas así, como diferentes (entrevista con informante $\mathrm{D}$, hombre, Cali, Colombia, 2 de febrero de 2015).

Pues normalmente pa' mi rumba yo me voy entaconada [en tacones], pero pa' ir allá [al "Petronio"] uno se va lo más cómodo posible, en tenis y lycras. Hay unos que sí se van con su vestido largo, turbantes en la cabeza, pero yo no (entrevista con informante $\mathrm{E}$, mujer, Cali, Colombia, 3 de febrero de 2015).

Algunas veces me pongo mi sombrero de paja, pero también me lo pongo pa' andar en mi calle [risas] (entrevista con informante C, mujer, Cali, Colombia, 3 de febrero de 2015).

Sobre este tipo de prácticas corporales habría que decir, en primera instancia, que estas ideas de vestirse como "afro" no tienen mucha correspondencia con la manera en que las personas afrocolombianas visten en su cotidianidad, ni siquiera en las zonas rurales, pues es extraño ver en estos espacios a mujeres con vestidos largos y estampados, que emulan más las tradiciones estéticas y de vestuario de África. Así, se estaría utilizando un recurso estético del vestuario que no está propiamente relacionado con lo afrocolombiano sino con una idea de lo "afro" en un universo más lejano, cultural e históricamente,

$9 \quad$ En esta entrevista se mencionan varios municipios y aires musicales del complejo cultural del Pacífico colombiano, dividido en tres grandes regiones sonoras: Pacífico norte, departamento del Chocó, donde las músicas características son las bandas de chirimía que interpretan ritmos europeos, como danza, contradanza, vals, polka; Pacífico sur, departamentos de Valle del Cauca, Cauca y Nariño, donde las agrupaciones musicales se caracterizan por el uso de marimbas de chonta y la interpretación de ritmos como jugas, arrullos, aguabjajos, patacorés; Pacífico interandino, departamentos de Cauca y Valle del Cauca, región que no limita con el Pacífico, sino que se ubica entre las cordilleras Central y Occidental, en las cuales se tienen más influencias de las músicas campesinas andinas mestizas del resto del país, como bambucos y pasillos, entre otros. 
tal vez un universo afrodiaspórico. De cualquier manera, no se puede generalizar a toda la población "afro" que asiste al Festival por la manera en que viste, en especial, con referencia a estos atuendos "tradicionales", situación que también está mediada por la idea de "lo que se pone de moda".

Sin embargo, entre los entrevistados no afrocolombianos existe el imaginario de que las personas "afro" visten de una manera particular para asistir al "Petronio", diferente a como ellos se disponen para ir, y no siempre mediada por el uso de prendas tradicionales "afro", sino también por lo elegante y lo sensual:

Las mujeres van, como dicen los de la costa pacífica, embambadas, es decir, emperifolladas, se adornan muy bien y generalmente van muy escotadas, con jeans o pantalones cortos y ceñidos y las blusas por lo general son diminutas. Y muy maquilladas, con turbantes y bisutería. Generalmente, la negra va muy bien vestida, llamativa (entrevista con informante A, mujer, Cali, Colombia, 15 de enero de 2015).

Vos vas allá a ver a la realeza de los afrodescendientes de Colombia [risas]. La gente supremamente bien vestida en el sentido del gusto occidental. Yo me sentía muy desarreglada yendo al "Petronio" en camiseta y short. Me sentía fuera de lugar, uno no ve casi "afros" vistiendo como yo, esa cosa como alternativa (entrevista con informante $\mathrm{F}$, mujer, Cali, Colombia, 10 de febrero de 2015).

\section{El Festival Internacional Afrocaribeño: encrucijadas del reconocimiento y la diferencia cultural entre el mestizaje y "la tercera raíz"}

El Festival Internacional Afrocaribeño comenzó en 1994 como un ejercicio académico y político para visibilizar los aportes de las culturas afrodescendientes a la cultura mexicana - denominadas por lo regular "la tercera raíz"-, con frecuencia ignorados en los relatos de identidad e historia nacional (Moreno,
2008; Malcomson, 2008; Rinaudo, 2008; 2012; Castañeda, 2012; Sue, 2013). ${ }^{10}$ Algunos antecedentes importantes que fundamentaron la idea fueron la instauración del Programa Cultural de las Fronteras (SEP, 1983) durante el gobierno de Miguel de la Madrid — que buscaba fomentar la investigación y el desarrollo cultural en las regiones fronterizas bajo la premisa de su diversidad cultural-y la creación del programa "Nuestra Tercera Raíz” (DGCP, 1989), enfocado en la visibilización de las herencias "afro" en las culturas regionales de la nación mexicana, por cuenta de Guillermo Bonfil Batalla en su gestión como director general de Culturas Populares del Consejo Nacional para la Cultura y las Artes (Conaculta).

El Festival consta de un foro académico, en el que se presentan charlas y conferencias sobre investigaciones relativas a estas culturas, y un foro artístico, que da cabida a presentaciones de agrupaciones musicales que interpretan ritmos propios o de fusión de tradiciones musicales relacionadas con estos universos culturales. El baile y la magnitud de la experiencia corporal festiva se asocian de manera directa al grupo que se presenta en el foro artístico. Las primeras presentaciones musicales del foro - alrededor de las 5:00 o 6:00 de la tarde - corren por cuenta de agrupaciones locales, por lo general de ritmos relacionados con el conjunto musical de son, jarocho y huasteco principalmente, o de artistas regionales

10 El estado de Veracruz, la región conocida como la Costa Chica de Oaxaca y el estado de Guerrero son, tal vez, los territorios de la República mexicana en los que hay un mayor reconocimiento de la influencia afrodiaspórica en la articulación de las prácticas y representaciones culturales e identitarias de sus habitantes, precisamente por su convivencia histórica con poblaciones afrodescendientes durante el periodo colonial y el siglo xIx. Dicho esto, en el imaginario nacional mexicano, "lo afro" es casi inexistente y concebido por lo regular como foráneo o anclado a un pasado que ya no existe o fue superado, idea soportada por el mito del mestizaje y la "raza cósmica", fomentada con gran fuerza desde las épocas posteriores a la Revolución mexicana (Sue, 2013). 
que interpretan ritmos de fusión entre estas músicas tradicionales y sonidos más contemporáneos. Durante estas primeras horas, es común ver un público compuesto por familias y personas de mayor edad que asisten con sus hijos o en pareja. Por lo general, los hombres mayores se presentan ataviados con guayaberas y sombreros, mientras que las personas más jóvenes no presentan mayor distinción en sus atuendos. La mayoría de los asistentes a estas presentaciones no responde a la música con baile y movimientos corporales, excepto por las demostraciones esporádicas de habilidades de zapateo y coreografías de pareja entre personas mayores, que son vistas con curiosidad por las personas menores, que se involucran poco en estas expresiones dancísticas.

Conforme avanza la noche, aparecen en escena grupos más reconocidos en los ámbitos nacional e internacional, lo que genera una mayor afluencia de públicos jóvenes, principalmente. Se percibe un descenso notable de asistentes de carácter más familiar y de mayor edad, quizá porque no conocen a muchas de las agrupaciones que se presentan a esas horas, más enfocadas en ritmos musicales contemporáneos. Según el tipo de agrupación que se presente, hay una mayor o menor intensidad de expresiones dancísticas por parte de los asistentes. Si la agrupación es de salsa o reggaetón, los asistentes buscarán una pareja para bailar al ritmo de la música. Si la agrupación interpreta ritmos de reggae, fusión o músicas africanas, hay una mayor preferencia por el baile individual o colectivo, o la mera contemplación del espectáculo. Incluso en algunas presentaciones de artistas famosos, que no encajan en ningún ritmo particular relacionado con lo afrocaribeño, el ambiente se torna más similar al de un concierto que al de un festival y los asistentes

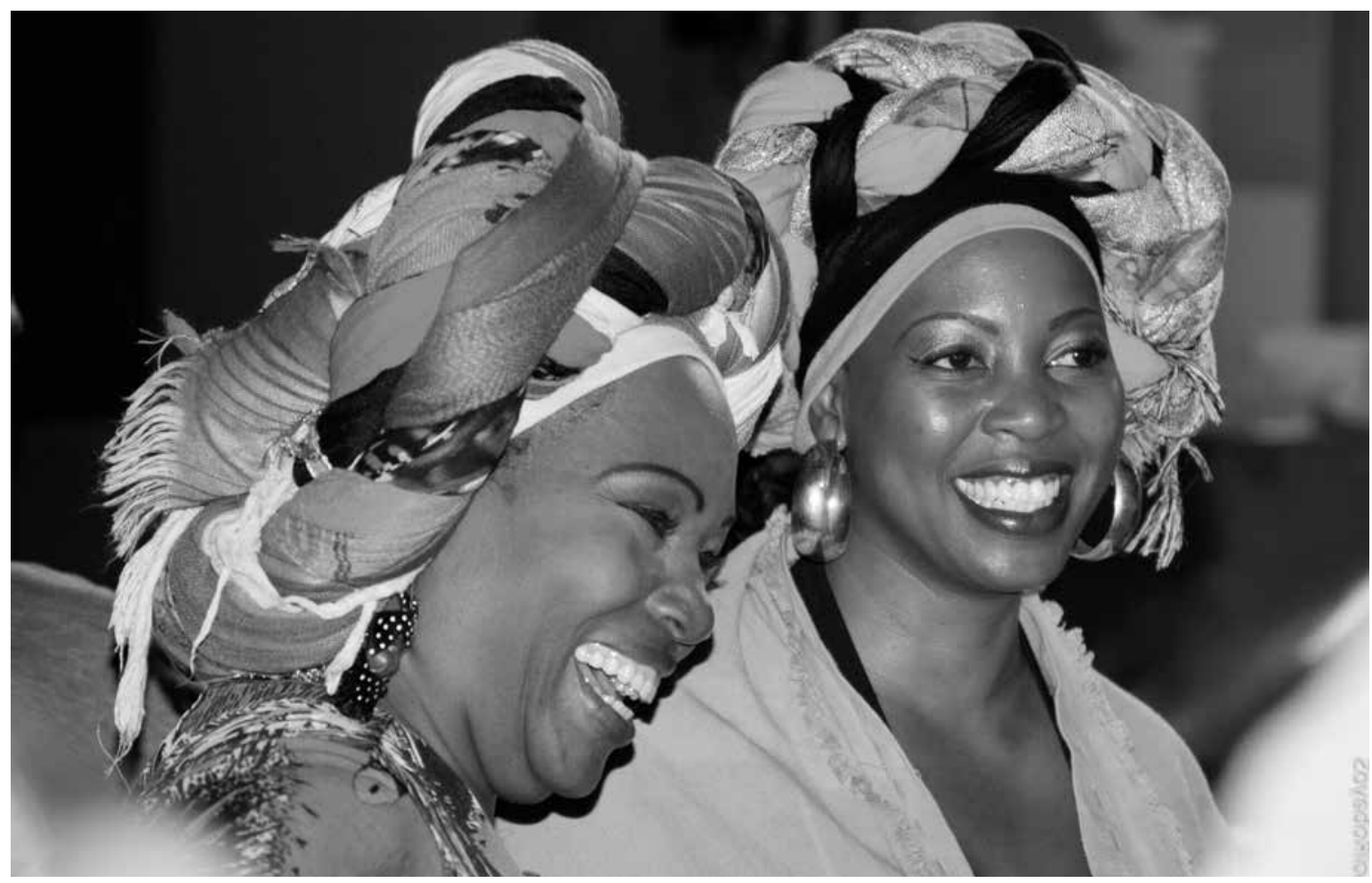

Sol Robayo • "Festival Petronio Álvarez", 23 de septiembre de 2013. 
responden a la música con saltos y coreando las canciones, pero no necesariamente bailando.

Ahora bien, ¿cómo se pueden leer las expresiones del multiculturalismo en los cuerpos, prácticas corporales y narraciones en las experiencias de los asistentes al foro artístico del Festival? Ante la pregunta de si habían experimentado o percibido diferencias entre las maneras de expresarse corporalmente y de bailar en el Festival de acuerdo con su autoidentificación étnico-racial, los entrevistados respondieron lo siguiente:

En la manera de bailar es lo mismo, todos tenemos alguna sangre negra por ahí metida y eso nos caracteriza a los jarochos, porque gracias a eso sabemos bailar muy bien, nos gusta mucho la alegría y el desmadre, sin importar si somos morenos o más claritos (entrevista con informante I, mujer, Veracruz, México, 3 de abril de 2015).

Personalmente, no veo una diferencia. Sí pienso que los "afro" bailan muy bien, pero cuando ves a estas personas con ese sabor, al menos a mí me dan ganas de moverme igual, de sacar esa raíz. Cuando voy al Festival, sale esa parte de mí y me siento parte de esto, siento que saca esa parte en mí que normalmente no la saco. Siento un sabor, así como de hermandad (entrevista con informante H, mujer, Xalapa, México, 1 de abril de 2015).

Se vive como una mímesis. Después de un tiempo de estar en ese lugar con tanto calor, movimiento... Pasa como con un rave, una fiesta: puede que no llegues con la expectativa de bailar, pero te encuentras con alguien que sabe bailar muy bien y entonces explotas y no necesitas más de una chela [cerveza] para volverte el alma de la fiesta. Sale la tercera raíz ahí. En el festival vives eso, vas a divertirte, a bailar, a sudar, puedes bailar con un desconocido y no pasa nada. Puedes hasta ligar [risas] (entrevista con informante G, hombre, Veracruz, México, 3 de abril de 2015).
En los fragmentos de estas entrevistas, vemos que aparece el mito de identidad nacional del mestizaje (Moreno, 2008; Malcomson, 2008; Rinaudo, 2008; 2012; Castañeda, 2012; Sue, 2013) como marcador de la manera en que estos asistentes al Festival Afrocaribeño perciben la diferencia, o mejor, la no diferencia entre las expresiones corporales mediadas por la variable étnico-racial. Así, recurren a la retórica de que "todos somos iguales", "todos estamos mezclados", la cual implica una "desracialización" de la población, que a su vez impide concebir y aceptar las prácticas racistas (Moreno, 2008). Recurren, además, a la idea de tener en alguna parte del cuerpo o de la información genética una especie de "chip afro", que se activa en determinados momentos y se expresa en el ámbito del baile y la fiesta. Sólo en una de las entrevistas apareció una clara diferenciación entre las maneras en que el baile es ejecutado por una categoría genérica de "los mexicanos" y otra, igualmente genérica, de "los africanos":

Digamos que tú ves a un africano acá [se levanta y hace movimientos exagerados con el cuerpo] y el mexicano acá [pasos disimulados, sin moverse mucho, pausados]. Y ya. Porque el hombre no va a hacer esto [movimiento exagerado de manos y caderas], porque le da pena, ya sería demasiado femenino. La mujer sí le entra, suavemente, pero le entra. Pero el hombre no se lo permite. Movimiento de hombros y caderas no hay. El bailar moviendo la cadera no se ve bien, para la mayoría de la gente. Los mexicanos somos así, con muchos complejos, reprimimos todo, como que no, no te pases de emoción (entrevista con informante G, hombre, Veracruz, México, 3 de abril de 2015).

Es significativo que esta narración haya sido elaborada por un músico que se identifica como "negro mexicano". Podríamos pensar que por su relación con el campo musical, en particular con el de 
tradiciones musicales africanas y afrodescendientes, tiene la habilidad de hacer esta diferenciación. También es significativo que, aunque se reconozca como "negro", se distingue y se coloca fuera o en ningún lugar de las dos categorías que analiza — "africanos" y "mexicanos"-, con lo que contribuye a la representación de lo "afro" como externo a la ciudadanía e identidad mexicana (Moreno, 2008), al tiempo que relata el aspecto de la percepción erótica de los tipos de baile "afro" por parte de la sociedad mestiza.

Aunque los asistentes entrevistados no reconocieron mayor diferenciación entre sus prácticas corporales de baile mediadas por la identificación étnico-racial, sí la reconocieron cuando se les interrogó en términos de si percibían esta diferencia respecto a personas de otras ciudades o regiones del país:

En Xalapa te das cuenta que tan cerca y tan lejos: es montaña, la gente es introvertida, introspectiva; en Veracruz, en cambio, la gente es muy extrovertida. Estamos tan sólo a $100 \mathrm{~km}$, pero es un mundo de diferencia cultural y sensorial (entrevista con informante $\mathrm{G}$, hombre, Veracruz, México, 3 de abril de 2015).

En la Ciudad de México la gente es más tranquila, más recatada, más correcta. Pero tú, aquí [Veracruz], vas a un parque, a un restaurant, tan sólo caminando por la calle y es una gritería, se hablan de una acera a otra, van en el carro y pitan. Tú no vas a ver en la ciudad de Veracruz que en las calles la gente esté calladita, tranquilita. Y otra cosa, respecto a la forma de bailar, un jarocho o jarocha te baila salsa apretadito y pegadito, así es nuestra forma de bailar; tú bailas así en otro estado y te dicen que te quieres sobrepasar (entrevista con informante I, mujer, Veracruz, México, 3 de abril de 2015).

Esta idea de diferenciarse de otras regiones del país, y en particular de otros lugares dentro del mismo estado - la ciudad de Xalapa se mencionó con frecuencia-, constituye un esfuerzo por articular una identidad "jarocha", propia de los habitantes de la ciudad de Veracruz. La "forma de ser jarocha" fue construida como estereotípica por elites mestizas mexicanas del siglo XIX y se perpetuó y consolidó en el siglo Xx. Se caracteriza por tener una influencia "afro", lo que la hace diferente del resto de la población mexicana: la bullanguería, la alegría, el humor, el desparpajo y la disposición para la fiesta y el baile (Pérez Montfort, 2007). De hecho, estos estereotipos sobre los jarochos son reconocidos y aceptados con orgullo por varios de los entrevistados que se reconocen así:

Nosotros somos costeños, somos de puerto, alegres, dicharacheros, gritones, gente franca, abierta. Nosotros necesitamos cualquier motivo, por más pequeño que sea, y hacemos una fiesta (entrevista con informante I, mujer, Veracruz, México, 3 de abril de 2015).

Yo creo que esa forma de ser de nosotros es por la influencia de los esclavos africanos. Dicen que somos alegres, de sangre caliente, dicharacheros, fiesteros, alegres, que nos gusta tomarnos los tragos, pasar un buen rato, bailar, disfrutar. Yo siento que es algo que los antepasados nos lo dejaron y ya nomás nosotros hicimos tantito para ser así [risas] (entrevista con informante J, hombre, Xalapa, México, 31 de marzo de 2015).

Si se contrastan los estereotipos asociados a los jarochos con los asociados a "lo negro" o "lo afro" en México —expuestos por Castillo (2003)—, se nota que son prácticamente los mismos: se aduce que son flojos, groseros, alegres, fiesteros, buenos bailadores, bulliciosos, peleoneros, que les gusta tomar licor; se destaca su hipersexualidad, en particular entre las mujeres. Es interesante resaltar que los jarochos rescatan los estereotipos asociados a lo "afro" o "negro" 
de carácter valorativo "bueno" — alegres, fiesteros, buenos para el baile - para incorporarlos a los relacionados con "lo jarocho", mientras que los "malos" — peleoneros, perezosos - se excluyen de los relatos de los entrevistados y de la idea general de la "identidad jarocha". A continuación, un fragmento de una narración que ejemplifica esta tensión:

A mí, hay cosas que me molestan, porque cuando saben que soy del Puerto me dicen que si es cierto lo que dicen de las jarochas, que somos calientes en la cama, como muy fogosas. Entonces ya piensan que soy caliente y entrona y todo eso; ése es un cliché que se nos ha puesto. Pero imagínate una costeña que sea así, seriecita, bien puestecita, calladita... pues no es costeña. Como, dime, un colombiano que no baile así abrazadito, pegadito, bien rico... pues no es colombiano [risas] (entrevista con informante K, mujer, Veracruz, México, 5 de abril de 2015).

Vemos entonces que la valoración y el rescate de "lo afro", en lo referente a las prácticas corporales y de baile entre los asistentes al Festival Afrocaribeño, están mediados por la elección de determinadas características asociadas a esta categoría, que se usan o no en ciertos momentos. Esto podría relacionarse con lo que Christian Rinaudo (2012) llama "africanidad electiva”, es decir, que la identificación con "lo afro" no pasa por la necesaria definición étnicoracial, sino por la performatización de determinadas formas de baile y expresión corporal que remiten a la idea de "lo afrocaribeño". Esta plasticidad del recurso de "lo afro" permite que se exalte o minimice cuando la situación particular lo amerite. Por otro lado, como menciona Hettie Malcomson (2008), mientras existe para algunos la posibilidad de "coquetear con lo negro", para otros no: "son demasiado 'visibles' (más oscuros en relación con otros) para no ser racializados y sus experiencias son muy diferentes. Ellos no pueden elegir si distanciarse o no de la 'negritud"” (Malcomson, 2008: 290).

\section{Encarnac(c)iones del multiculturalismo en contextos festivos afromusicales en Latinoamérica}

Quisiera hablar de la discusión sobre las corporalidades de los asistentes a estos festivales por medio del concepto de encarnación/encarnacción. La idea de la encarnación del proyecto multicultural en las prácticas y representaciones corporales de los sujetos que asisten a estos dos eventos es útil para entender cómo este discurso toma carne y se (re)produce, pero también para comprender la situación como una acción, una "encarnacción”, es decir, una performatización de los cuerpos de las personas que se ven interpeladas en el tipo de contextos de los festivales afromusicales por los preceptos multiculturales.

Para analizar las "encarnac(c)iones" del multiculturalismo, retomo la caracterización de Brian Turner sobre "la forma del deseo", definida como "el conjunto de relaciones sociales a través del cual el deseo sexual es producido, regulado y distribuido bajo un sistema de parentesco, patriarcado y familias" (1989: 38-39). Desde una perspectiva marxista, el autor propone que la construcción de las relaciones sociales del deseo es presupuesta y regulada por las relaciones de producción de cada sociedad. Esto implica que, en las sociedades capitalistas contemporáneas, el deseo está construido y mediado por el proceso de mercantilización y constante fabricación - y consumo - de necesidades y placeres (Muñiz, 2004), lo cual imposibilita, en lo teórico y en lo práctico, la satisfacción del deseo mismo.

Entonces, en la "forma del deseo" del multiculturalismo contemporáneo en Latinoamérica, los sujetos se constituyen de manera diferenciada según su adscripción étnico-racial, determinada por el orden social, productivo y corporal instaurado en nuestras naciones bajo la hegemonía del Estadonación blanco-mestizo. A pesar de las enormes diferencias en los procesos históricos de conformación de la alteridad étnico-racial "afro" en México y 
Colombia - una presencia invisibilizada y olvidada en la historia oficial, en el primer caso; en contraste con una numerosa y evidente influencia y existencia contemporánea, aunque no por ello necesariamente exaltada como motivo de orgullo nacional, en el segundo-, es posible evidenciar algunos elementos comunes que responden a la estructura del proyecto político multicultural en la región.

De este modo, la racialización de los cuerpos y el deseo sexual ha implicado en muchas ocasiones la cosificación y fetichización de las alteridades étnicas en términos sexuales, tanto como objeto del deseo como de repugnancia (Wade, 2008b). Los cuerpos de la otredad subalternizada, en este caso una otredad "afro", son representados por el yo blanco-mestizo a partir de una serie de estereotipos, ya mencionados, que remiten al estado de salvajismo o de "menor grado de civilización" de estas poblaciones - y sus disposiciones corporales - en relación con las mayorías mestizas que se ubican en el lugar privilegiado del cuerpo occidental moderno: pulcro, incólume, ascético, inmaculado, un cuerpo sin carne, descorporeizado (Le Breton, 2005). Las corporalidades "afro" aparecen entonces como peligrosas en relación con las corporalidades mestizas hegemónicas, como símbolos que parecen funcionar como un tabú contaminante, en el sentido de que pueden evocar el lugar en el que las corporalidades blanco-mestizas no quieren estar o incluso al que no quieren regresar: el lugar del cuerpo más cercano a la naturaleza, lo primitivo, lo material, lo carnal mismo.

Las entidades estatales locales encargadas de la organización de los festivales han reforzado estos estereotipos mediante la articulación de los discursos de promoción y performatización de los eventos — con los carteles publicitarios, los discursos retóricos sobre "las raíces africanas", los guiones de los presentadores-, lo cual ha surtido efecto en los imaginarios, representaciones y prácticas de los asistentes. Aun así, la perpetuación de estos estereotipos no puede atribuirse sólo a la acción deliberada de los proyectos de los festivales estipulados por las instituciones organizadoras. Éste es un proceso de larga duración que se ha constituido como un ejercicio de (bio)poder que comienza en el periodo colonial y que, aunque con algunas modificaciones, se ha mantenido vigente hasta la contemporaneidad (Viveros, 2000; Restrepo, 2007).

Para el caso de los asistentes al Festival Afrocaribeño en Veracruz, a pesar de que no hay un autorreconocimiento diferenciado como negros, afromexicanos o afrodescendientes entre la mayoría de los entrevistados, sí reivindican que tienen “el sabor”, por haber nacido en la ciudad y en la región — por ser jarochos—, gracias a sus antepasados de ascendencia africana, muy remotos o no, quienes les "legaron en la sangre" esta cualidad, apta para tener una mayor libertad corporal, tanto en su expresividad cotidiana como en sus prácticas específicas - las más relevantes son las del campo del baile y la música, pero también hay otras, como las sexuales-. Es necesario recalcar que, aunque los habitantes de Veracruz se reconozcan en estas cualidades aportadas por "la tercera raíz" y las personas de otros estados del país, que no reconocen ningún vínculo con las poblaciones africanas o afroamericanas, también se las reconozcan, no quiere decir que la diferencia entre la construcción de los cuerpos de las personas de esta región y la de los asistentes al Festival Afrocaribeño sea tan significativa como para reconocerse como “cuerpos afro". Ésos son los que están retratados en los materiales publicitarios: cuerpos extranjeros, hiperexóticos y radicalmente diferentes a los ciudadanos mexicanos, incluso a los veracruzanos. Los veracruzanos tienen la posibilidad de jugar con su herencia "afro", exaltarla o invisibilizarla según la situación, pero nunca encarnarla de manera que se cuestione su pertenencia a la sociedad mexicana que, desde su institucionalidad y el común de sus ciudadanos, en casi nada se reconoce como heredera o vinculada a los procesos 


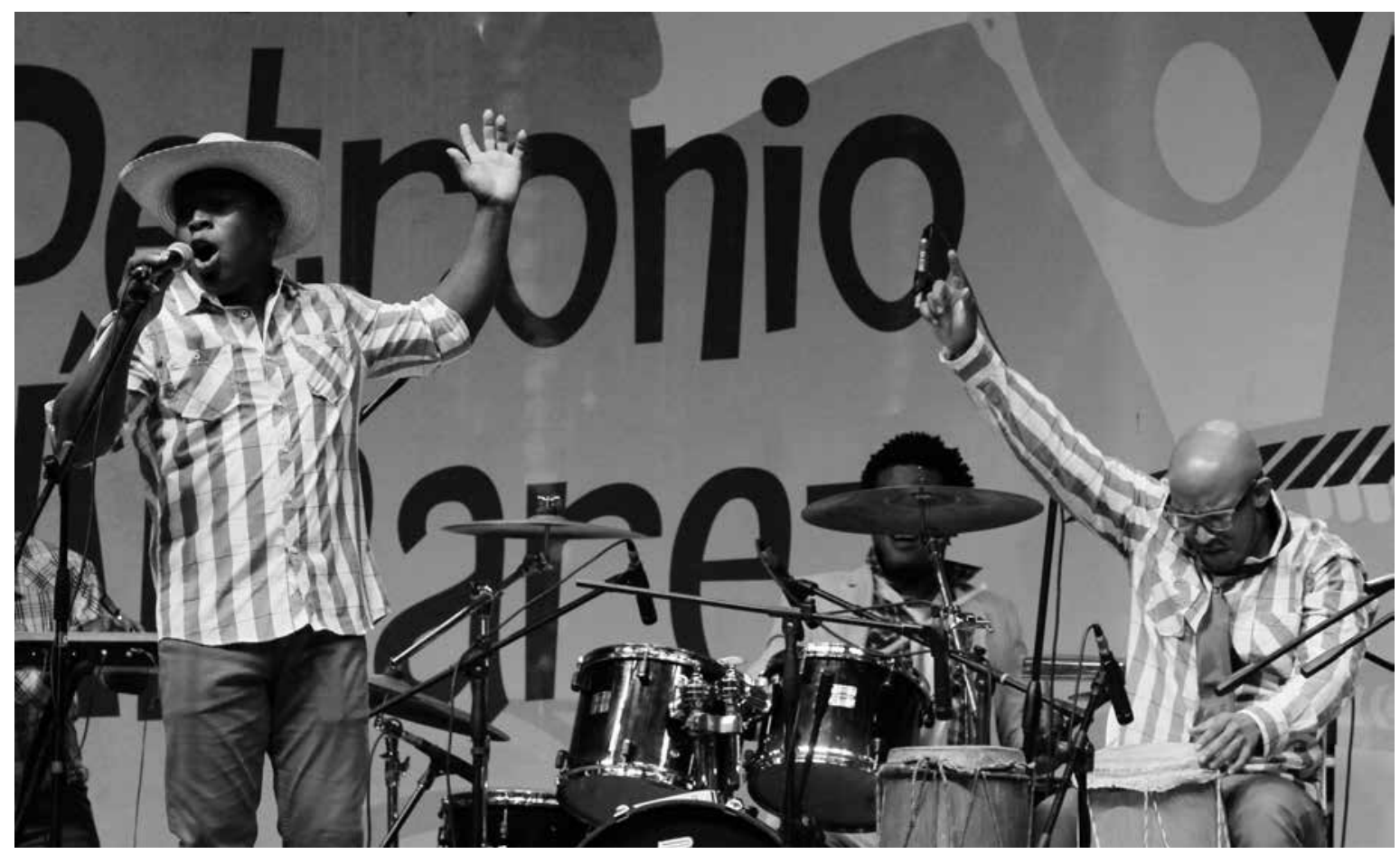

RodRIGo Rodriguez - Grupo Marimba y son, en rondas clasificatorias del Festival "Petronio Álvarez”, 19 de septiembre de 2013.

socioculturales de las poblaciones afrodescendientes en el continente americano (Sue, 2013).

En el caso del Festival "Petronio Álvarez", en Cali, las distinciones corporales son más marcadas en la medida en que hay un mayor reconocimiento y diferencia étnico-racial entre los asistentes. Por una parte, los mestizos, al igual que en el caso mexicano, reconocen que las personas afrodescendientes tienen "el sabor en la sangre", lo que les permite tener una expresión corporal más libre y relajada que ellos, razón por la cual son mejores en el baile y en otras actividades que implican el uso del cuerpo - desde el desempeño sexual hasta las actividades de fuerza bruta-. En este sentido, los mestizos entrevistados denotan una idealización de las corporalidades "afro", que en ocasiones socialmente aceptadas, como estos escenarios festivos, intentan imitar mas no igualar. Por otra parte, las personas afrodescendientes que asisten a este evento también reconocen que son "portadoras del sabor" en sus cuerpos, aunque matizan esta exotización con estrategias en las que se reconocen como diferentes entre sí mismos y no caen con tanta facilidad en las generalizaciones sobre sus expresiones corporales, como los entrevistados mestizos, bajo la lógica de su régimen de representación (Hall, 1997). ${ }^{11}$ Asimismo, los asistentes afrodescendientes reconocen los estereotipos con los que su imagen corporal e identitaria es construida por los asistentes mestizos. Estos últimos son representados como desconocedores de las expresiones tradicionales de las poblaciones afrocolombianas, mas no necesariamente

11

Hall (1997) define el "régimen de representación" como la forma en que la diferencia y la otredad se representan en una cultura particular en un momento histórico específico, los significados y referentes intertextuales que esto implica, así como su repertorio de imágenes y efectos visuales. 
como ejecutantes de juicios racistas en este tipo de prácticas de representación.

En el caso colombiano, hemos mencionado que el baile es un elemento fundamental de la experiencia de asistencia al Festival "Petronio Álvarez". Dado que prácticamente la totalidad de las músicas que se interpretan en este evento se catalogan como tradicionales, su apropiación es inevitable y no pasa por el filtro académico o purista de evaluar si la manera en que se baila esta tradición es la correcta o no. Es muy probable que haya personas que estén en desacuerdo con la banalización de una tradición musical cuando la baila una persona que no tiene el menor conocimiento sobre ella, pero en este escenario podríamos defender que la tradición, en efecto, se está interpretando, performatizando y actualizando al son de las personas interesadas, con independencia de su bagaje cultural previo.
En el caso del Festival Afrocaribeño, el baile de la música tradicional — representada por el son jarocho- continúa limitado a la población de mayor edad que asiste al evento, con lo que "anticuariza" estas tradiciones, impide su apropiación y actualización en las nuevas generaciones de habitantes de la ciudad, y tiene en cuenta la efectiva inmovilidad, es decir, la no interpelación de estas músicas en los cuerpos de las personas más jóvenes, que esperan las presentaciones de la música que a ellos les interesa o les interpela, la música más contemporánea, como reggaetón, salsa, reggae.

Por otra parte, la gama de "tecnologías corporales" que elaboran los asistentes a estos festivales, al margen de su adscripción étnico-racial, en su idea de "parecer negros", de acercarse más a la experiencia de "lo negro" que se intenta performatizar en ambos escenarios - los turbantes, los estilos de peinado

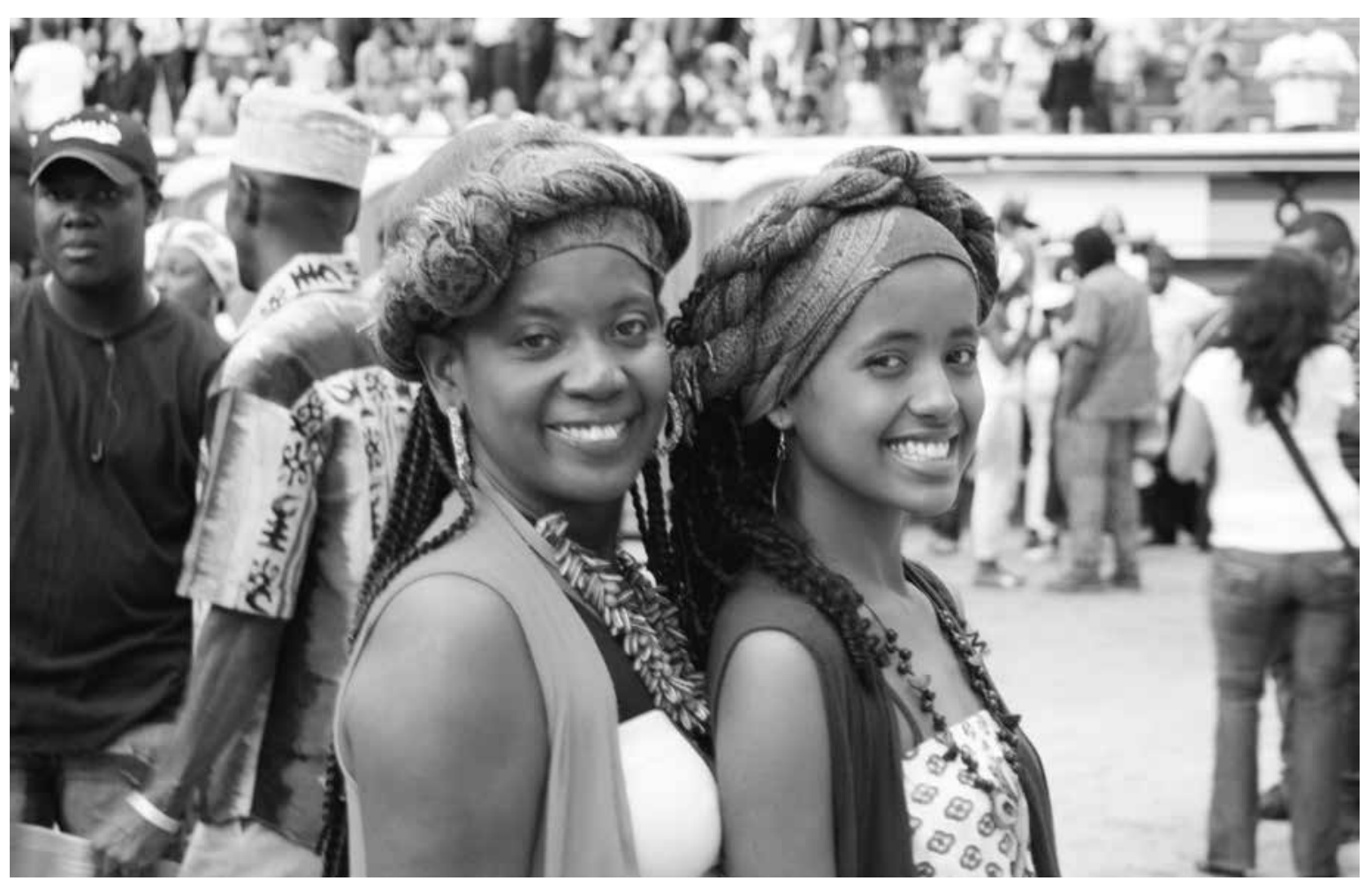

Alejandro Serrano Durán • Rostros del "Petronio". 
como las trenzas o los dread locks, las guayaberas, entre otros-, son representaciones mediadas por el exotismo, los estereotipos y lo que en el ámbito internacional se reconoce como "afro". El hecho de que incluso personas que se autorreconocen como afrodescendientes recurran a esta especie de caja de disfraces para resaltar una tradición imaginada, nos pone en un terreno movedizo en el que habría que cuestionarse la relevancia o no de este tipo de prácticas.

\section{Reflexiones finales}

A lo largo de este documento, se ha tratado de demostrar la importancia de analizar las maneras en que las estructuras de representación hegemónicas que proyecta el discurso multicultural no sólo se ubican en las esferas macrosociológicas de las sociedades latinoamericanas, como la organización político-administrativa o los sistemas legislativos, también se insertan y se encarnan en los cuerpos de los ciudadanos de estos Estados-nación por medio de estrategias biopolíticas históricamente configuradas y en constante actualización, que tienen la habilidad de instaurar y recrear representaciones y prácticas que median en la perpetuación de formas de estigmatización y discriminación hacia las poblaciones diversas étnica y culturalmente.

Aunque los escenarios festivos que hemos analizado se plantean como espacios de promulgación y respeto hacia la diversidad étnico-cultural de Colombia y México, el régimen de representación multicultural sobre las corporalidades "otras", en este caso afrocolombianas o afromexicanas, reproduce los lugares sociales históricamente configurados para estas poblaciones y sus cuerpos, lo que conlleva la perpetuación de las asimetrías en las relaciones de estas ciudadanías interculturales. La construcción subjetiva de la identificación y diferenciación corporal entre los sujetos que asisten a estos festivales rearticula las estructuras de subalternidad de las poblaciones "afro", en particular con prácticas y relatos que evidencian el racismo de una manera un poco menos explícita o frontal. Antes, durante y después de estos momentos festivos, los cuerpos de las personas asistentes siguen estando igual de racializados, y por consiguiente, cargan su significación biopolítica dentro de las lógicas de construcción ciudadana de los Estados-nación de la región.

Es necesario considerar los estudios del multiculturalismo relacionados con el análisis sobre las corporalidades, en la medida en que son algunos de los escenarios clave en los que se pueden demostrar algunas falacias del proyecto multicultural en Latinoamérica, pues no genera condiciones materiales y subjetivas que lleven a la inclusión efectiva y el respeto hacia esta diversidad cultural, sino que, por el contrario, conducen a la perpetuación de estereotipos y barreras - que en este caso comienzan en lo corporal y trascienden hacia lo ideológico- que impiden el reconocimiento de la igualdad en la diferencia y el intercambio dialógico de experiencias y trayectorias culturales. D

\section{Bibliografía}

Birenbaum Quintero, Michael, 2012, "De ritos a ritmos: las prácticas musicales afropacíficas en la época de la etnodiversidad", en Eduardo Restrepo (ed.), Estudios afrocolombianos hoy: aportes a un campo transdisciplinario, Universidad del Cauca, Popayán, pp. 159-187. Breton, David Le, 2005, Antropología del cuerpo y modernidad, Nueva Visión, Buenos Aires.

Carvalho, José Jorge de, 2004, "Las tradiciones musicales afroamericanas: de bienes comunitarios a fetiches transnacionales", en Jaime Arocha (comp.), Utopía para los excluidos: el multiculturalismo en África y América Latina, Universidad Nacional de Colombia-Centro de Estudios Sociales, Bogotá, pp. 47-78. 
Castañeda, Ángela, 2012, "Performing the African Diaspora in Mexico", en Kwame Dixon y John Burdick (eds.), Comparative Perspectives on Afro-Latin America, University Press of Florida, Gainesville, pp. 93-113.

Castillo Gómez, Amaranta Arcadia, 2003, “Los estereotipos y las relaciones interétnicas en la Costa Chica oaxaqueña”, en Revista Mexicana de Ciencias Políticas y Sociales, vol. 46, núms. 188-189, pp. 267-290.

Citro, Silvia, Patricia Aschieri y Yanina Mennelli, 2011, “El multiculturalismo en los cuerpos y las paradojas de la desigualdad colonial”, en Boletín de Antropología, vol. 25, núm. 42, pp. 102-128.

Congolino Sinisterra, Mary Lilia, 2008, “¿Hombres negros potentes, mujeres negras candentes? Sexualidades y estereotipos raciales. La experiencia de jóvenes universitarios en Cali, Colombia”, en Peter Wade, Fernando Urrea Giraldo y Mara Viveros Vigoya (eds.), Raza, etnicidad y sexualidades, Universidad Nacional de Colombia, Bogotá, pp. 317-342.

Departamento Administrativo Nacional de Estadística (DANE), 2006, Censo general 2005, Departamento Administrativo Nacional de Estadística, Bogotá.

Desmond, Jane, 2003, "Embodying Difference: Issues in Dance and Cultural Studies”, en Jane Desmond (ed.), Meaning in Motion: New Cultural Studies of Dance, Duke University Press, Durham, pp. 29-54.

Dirección General de Culturas Populares (DGCP), 1989, Programa Nuestra Tercera Raíz, Consejo Nacional para la Cultura y las Artes, México. Gros, Christian, 2000, Políticas de la etnicidad, Instituto Colombiano de Antropología e Historia, Bogotá.

Guss, David, 2000, The Festive State: Race, Ethnicity, and Nationalism, as Cultural Performance, University of California Press, Berkeley.

Hall, Stuart, 1997, “The Spectacle of the Other”, en Stuart Hall (ed.), Representation: Cultural Representations and Signifying Practices, Sage Publications, Londres, pp. 223-290.

Malcomson, Hettie, 2008, “La configuración racial del danzón: Ios imaginarios raciales del puerto de Veracruz", en Elisabeth Cunin (coord.), Mestizaje, diferencia y nación. Lo "negro" en América Central y el Caribe, Instituto Nacional de Antropología e Historia/Centro de Estudios Mexicanos y Centroamericanos/Universidad Nacional Autónoma de México-Centro de Investigaciones sobre América Latina y el Caribe/Institut de Recherche pour le Développement, México, pp. 267-298.

Moreno Figueroa, Mónica, 2008, "Mestizaje, cotidianeidad y las prácticas contemporáneas del racismo en México", en Elisabeth Cunin (coord.), Mestizaje, diferencia y nación. Lo "negro" en América Central y el Caribe, Instituto Nacional de Antropología e Historia/Centro de Estudios Mexicanos y Centroamericanos/Universidad Nacional Autónoma de México-Centro de Investigaciones sobre América Latina y el Caribe/Institut de Recherche pour le Développement, pp. 129-170.

Muñiz, Elsa, 2004, "Multiculturalismo, cuerpo y género: un debate contemporáneo", en Fuentes Humanísticas, núm. 28, pp. 29-41.

- 2013, “Del mestizaje a la hibridación corporal: la etnocirugía como forma de racismo”, en Nómadas, núm. 38, pp. 81-97.

Pérez Montfort, Ricardo, 2007, Expresiones culturales y estereotipos culturales en México, siglos xix y xx. Diez ensayos, Centro de Investigaciones y Estudios Superiores en Antropología Social, México.

Restrepo, Eduardo, 2004, Teorías contemporáneas de la etnicidad. Stuart Hall y Michel Foucault, Universidad del Cauca, Popayán.

—_, 2007, “Imágenes del 'negro' y nociones de raza en Colombia a principios del siglo xx”, en Revista de Estudios Sociales, núm. 27, pp. 46-61.

Rinaudo, Cristian, 2008, “Más allá de la 'identidad negra': mestizaje y dinámicas raciales en la ciudad de Veracruz", en Elisabeth Cunin (coord.), Mestizaje, diferencia y nación. Lo "negro" en América Central y el Caribe, Instituto Nacional de Antropología e Historia/Centro de Estudios Mexicanos y Centroamericanos/Universidad Nacional Autónoma de México-Centro de Investigaciones sobre América Latina y el Caribe/Institut de Recherche pour le Développement, México, pp. 225-266.

, 2012, Afromestizaje y fronteras étnicas. Una mirada desde el puerto de Veracruz, Universidad Veracruzana, Xalapa.

Secretaría de Educación Pública (SEP), 1983, Programa Cultural de las Fronteras, Secretaría de Educación Pública, México.

Segato, Rita Laura, 2007, La nación y sus otros. Raza, etnicidad y diversidad religiosa en tiempos de políticas de la identidad, Prometeo Libros, Buenos Aires.

Sue, Christina, 2013, Land of the Cosmic Race. Race Mixture, Racism and Blackness in Mexico, Oxford University Press, Nueva York. Turner, Brian, 1989, El cuerpo y la sociedad, Fondo de Cultura Económica, México.

Viveros, Mara, 2000, "Dionisios negros. Estereotipos sexuales y orden racial en Colombia”, en Mario B. Figueroa Muñoz y Pío E. Sanmiguel (eds.), ¿Mestizo yo? Diferencia, identidad e inconsciente, Universidad Nacional de Colombia-Facultad de Ciencias Humanas, Bogotá, pp. 95-130.

Wade, Peter, 2000, Raza y etnicidad en Latinoamérica, Abya-Yala, Quito. 
,2008a, "La presencia de lo negro en el mestizaje", en Elisabeth Cunin (coord.), Mestizaje, diferencia y nación. Lo "negro" en América Central y el Caribe, Instituto Nacional de Antropología e Historia/Centro de Estudios Mexicanos y Centroamericanos/Universidad Nacional Autónoma de México-Centro de Investigaciones sobre América Latina y el Caribe/Institut de Recherche pour le Développement, México, pp. 107-127.

,2008b, "Población negra y la cuestión identitaria en América Latina”, en Universitas Humanística, núm. 65, pp. 117-137.

Walmsley, Emily, 2005, “'Bailando como negro': ritmo, raza y nación en Esmeraldas, Ecuador”, en Tabula Rasa, núm. 3, pp. 179-195.

\section{Entrevistas}

Informante A, mujer, Cali, Colombia, 15 de enero de 2015.

Informante B, hombre, Buga, Colombia, 24 de enero de 2015.

Informante C, mujer, Cali, Colombia, 10 de enero y 3 de febrero de 2015.

Informante D, hombre, Cali, Colombia, 2 de febrero de 2015.

Informante E, mujer, Cali, Colombia, 3 de febrero de 2015.

Informante F, mujer, Cali, Colombia, 10 de febrero de 2015.

Informante G, hombre, Veracruz, México, 3 de abril de 2015.

Informante H, mujer, Xalapa, México, 1 de abril de 2015.

Informante I, mujer, Veracruz, México, 3 de abril de 2015.

Informante J, hombre, Xalapa, México, 31 de marzo de 2015.

Informante K, mujer, Veracruz, México, 5 de abril de 2015. 